\title{
Improving Environmental Scanning Systems Using Bayesian Networks
}

Simon Welter, A.T. Kearney GmbH, Germany, E-mail: simon.welter@atkearney.com

Jörg H. Mayer, Institute of Information Management, University St. Gallen, Switzerland, E-mail: joerg.mayer@unisg.ch

Reiner Quick, Department of Accounting and Auditing, Darmstadt University of Technology, Germany, E-mail: quick@bwl.tu-darmstadt.de

\begin{abstract}
As companies' environment is becoming increasingly volatile, scanning systems gain in importance. We propose a hybrid process model for such systems' information gathering and interpretation tasks that combines quantitative information derived from regression analyses and qualitative knowledge from expert interviews. For the latter, we apply Bayesian networks. We derive the need for such a hybrid process model from a literature review. We lay out our model to find a suitable set of business environment indicators to forecast a company's key financials. Deriving lessons learned from a prototype in the industrial sector, we evaluate the utility of our model following the design science research paradigm. We find our model to especially convince in completeness, transparency and transportability when compared with "pure" mathematical models.
\end{abstract}

JEL classification: Co2, C11, C53, G17, M49

Keywords: corporate management, balancing opportunities and threats, regression analyses, Bayesian networks, information systems (IS) design, design science research in IS, case study

Manuscript received September 12, 2012, accepted by Karl Inderfurth (Operations and Information Systems) April 24, 2013.

\section{$1 \quad$ Introduction}

As their environment today is more volatile than ever (Chang, Lai, and Lai 2006; Cinar and Kayakutlu 2010), managing companies has become increasingly complex. In recent times, the 2008/2009 economic crisis provided a strong impulse for companies to focus earlier on emerging threats and opportunities (Makridakis, Hogarth, and Gaba 2010). Executives worry about not being prepared for environmental shifts or, even worse, not being able to parry them.

Environmental scanning can help to manage this challenge, especially if it is information systems (IS)based (Rohrbeck 2012); companies that do so will have brighter prospects (Ansoff 1980). The main functions of such scanning systems are to gather, interpret, and use pertinent information about events, trends, and relationships in an organization's environment to assist management in planning the future course of action (Aguilar 1967; Lenz and Engledow 1986).

With Ansoff's (1975) "Managing Strategic Surprise by Response to Weak Signals" as a flagship article, a substantial body of knowledge on this topic exists, but concepts often lack utility in practice (Lesca and Caron-Fasan 2008). Practitioners perceive the task as a difficult one per se (Aaker 1983) and encounter obstacles in the conceptual design, implementation, and day-to-day operation of scanning systems.

Mayer (2012) came up with five ways to improve today's environmental scanning systems: (1) design a more comprehensive information model, (2) set 
up a collective learning process for interpreting information, (3) use IS to enable management techniques familiar to executives, (4) design processes for more interorganizational integration, and (5) accelerate prototyping.

To enable a fact-driven decision-making process and additional time for proactive management, we focus on the first two areas of this list: information gathering and interpretation. In addition to mathematical approaches to these scanning tasks such as ARIMA (Ediger and Akar 2007), newer approaches such as artificial neural networks (Lam 2004) and simulation (McDoniel and Monteleone 2001) are gaining importance (Kuo and Xue 1998). Bayesian networks (BNs) in particular have been applied successfully in areas such as computer science, medical diagnosis, and operational risk management (Pourret, Naim, and Marcot 2008). Particularly with the emerging challenges of "big data" phenomena, BNs are gaining importance as they can manage the increasing scale and complexity of data (Schadt, Linderman, Sorenson, Lee, and Nolan 2010). However, we found no examples of environmental scanning system design that integrates BNs. The objective of this article is to develop a hybrid process model that combines quantitative information for environmental scanning systems derived from regression analyses and qualitative knowledge from expert interviews. For the latter, BNs are applied to elicit and illustrate even complex relationships between business environment indicators (BEIs) and key financials.

Following Gregor (2006), models can be evaluated for completeness, simplicity, consistency, ease of use, and the quality of results through the use of methods. Simon (1996) sees "interestingness" as a valid claim. Following the design science research (DSR) paradigm we focus on utility of our model (Baskerville 2012; Österle, Becker, Frank, Hess, Karagiannis, Krcmar, Loos, Mertens, Oberweis, and Sinz 2010). We propose our hybrid process approach to forecast company's key financials as more applicable than "pure" mathematical models specified by previous research (Cinar and Kayakutlu 2010). In doing so, we answer two research questions:

- How can BNs be applied in the domain of environmental scanning systems and what results can be expected?

- Are there patterns to arrive at a suitable set of business environment indicators (comprehen- sive in terms of content, but condensed in terms of its information presentation) to forecast company's key financials?

Our investigation adheres to DSR in IS, which aims to create useful artifacts that solve relevant design problems in organizations (Hevner, March, Park, and Ram 2004). Focusing on "build" and "evaluate" activities, the remainder of this article is structured as follows (Peffers, Tuunanen, Gengler, Rossi, Hui, Virtanen, and Bragge 2006): After revisiting foundations (sect. 2) and laying out regulatory needs (sect. 3), we perform a literature review to identify concepts for environmental scanning (sect. 4). We then present our hybrid model (sect. 5) and demonstrate its utility with a prototype in a single case study (sect. 6). The lessons learned help us to evaluate our model (sect.7). Finally, we provide starting points for future research (sect. 8).

\section{Foundations}

Based on our prior work (Mayer, Steinecke, Quick, and Weitzel 2012), a company's environment is defined as the relevant physical and social factors within and beyond the organization's boundaries (Duncan 1972). While operational analysis focuses on (short-term) internal difficulties in the implementation of strategic programs (Davies, Finlay, McLenaghen, and Wilson 2006), strategic environmental scanning aims at anticipating (longterm) environmental shifts and analyzing their potential impact. This article concentrates on the latter, hereafter referred to as environmental scanning.

Environmental scanning systems have their roots in management literature (Aguilar 1967) focusing on the awareness of environmental trends as an executive task (Narchal, Kittappa, and Bhattacharya 1987). Such systems specify the sectors to be scanned, monitor important indicators of opportunities and threats for the company, cover IS-based tools to be used, incorporate the analytical findings into executives' decision making and, in many cases, assign responsibilities to support environmental scanning. In a reactive mode, scanning acquires information to resolve problems. We follow the proactive mode, which involves scanning the environment for upcoming opportunities and threats (Choudhury and Sampler 1997).

Economic indicators identify and analyze business cycles (Boehm and Summers 1999). These indi- 
cators can be leading, coincident or lagging - in other words, they can anticipate, occur in conjunction with, or follow movements of the economy - and are evaluated in terms of their economic significance, statistical adequacy, and the lead time with which they point to future economic activities and prospects (Stratford 1988). Weak signals identify threats or opportunities to an organization at a very early stage, when data are vague and not causally connected (Ansoff 1975). We focus on business environment indicators. These leading indicators of business performance cover both, external factors such as economic indicators and weak signals, and internal information such as customer complaint rates, production time, or scrap rates.

\section{$3 \quad$ Regulatory Needs}

Specifying Kajüter's (2004) statement that environmental scanning systems are not just "nice to have," several regulatory needs must be considered for a proper design. In the wake of cases of fraud around the turn of the millennium that were detected neither by internal controls nor by auditors, legislators expressed a need for more detailed risk management approaches. Best known is the U.S. Sarbanes-Oxley Act. In particular, Section 404 requires companies with securities traded in the U.S. to establish and maintain an adequate internal control structure and procedures for financial reporting. Furthermore, the annual report must contain an assessment of the effectiveness of these control structures and procedures, which the management must attest to and auditors have to comment on in the audit report (Krishnan, Rama, and Zhang 2008; Sherman and Chambers 2009).

As another example, § $91 \mathrm{II}$ of the German Stock Corporation Act requires companies to implement early warning systems. Furthermore, capital-market-oriented companies must describe their internal controls and risk management in their annual management report (\$ 289, German Commercial Code). Additionally, the code requests the evaluation of the company's prospective development and perceived opportunities and risks. Last, but not least, financial statements are prepared on the assumption that a company will continue to operate for the foreseeable future (IASB Conceptual Framework 4.1; IAS 1.25), making forecasts of at least one year necessary.

\section{Figure 1: Results of a current literature review}

(expanded illustration based on Mayer, Steinecke, Quick, and Weitzel 2012; Mayer, Steinecke, and Quick 2011)

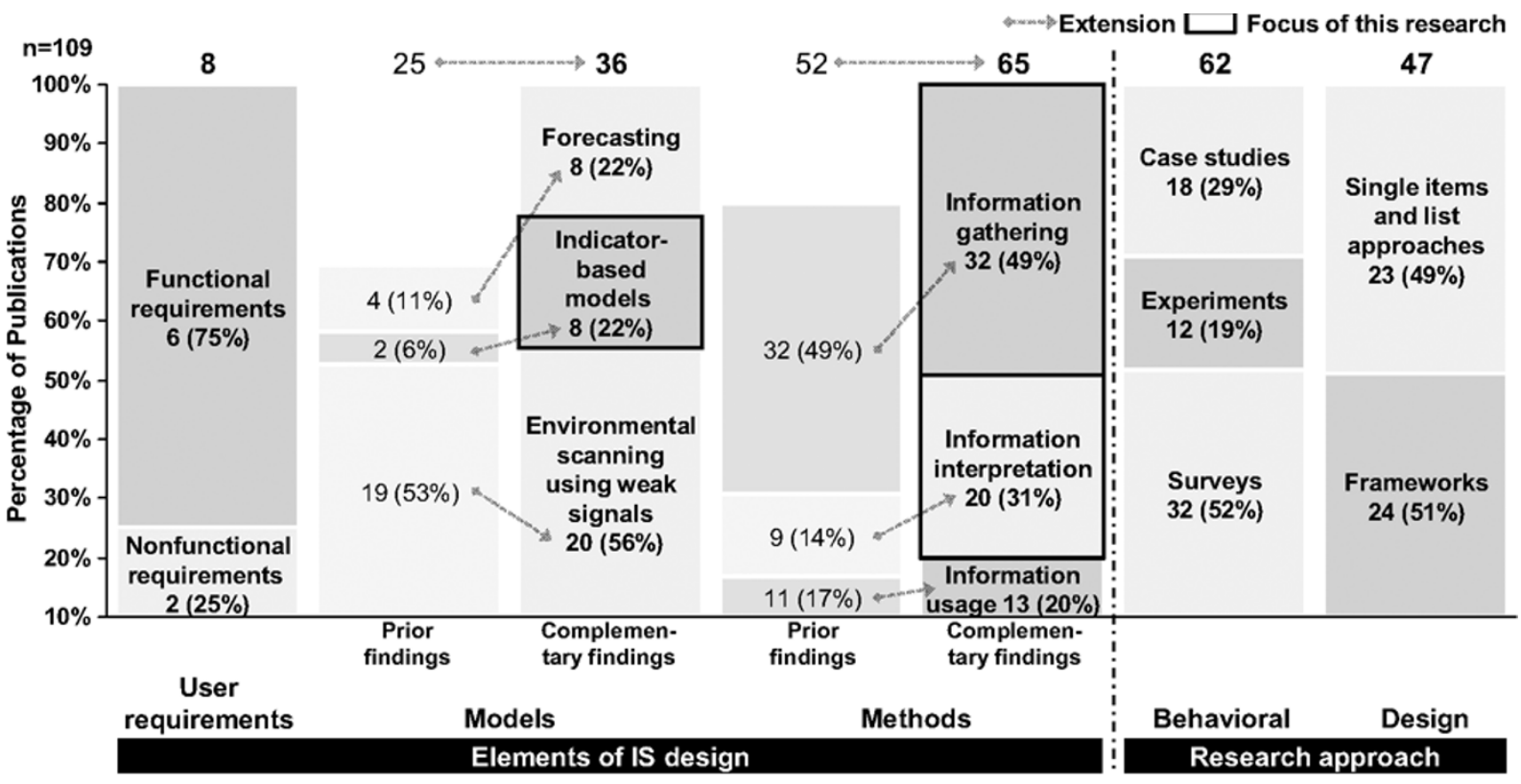




\section{State of the Art}

\subsection{Prior Work}

According to Webster and Watson (2002), a literature review should be concept-centric. Elements of IS design theories - (user) requirements, models, and methods - combined with the research approach applied offer a rigorous framework for structuring the literature (Mayer, Steinecke, and Quick 2011). Figure 1 illustrates the following research gaps:

Sound requirements analysis is missing (Figure 1, first column left): Most of the publications, for example Frolick, Parzinger, Rainer Jr., and Ramarapu (1997), follow a simple list approach without providing an overall structuring principle or secondlevel dimensions. None of the remaining approaches apply a systematic process to develop requirements criteria for environmental scanning systems. Weak signals lack the "grasp" to apply in practice (second and third column left): The most popular approach for proactive decision making is the use of weak signals. We pursue this concept, but attempt to improve the "grasp" of these signals. In particular, it is not clear which environmental changes actually constitute weak signals.

Approaches to closely incorporate environmental scanning results into executives' decision making are missing (fourth and fifth column left): Environmental scanning is futile if the results are not integrated into executives' decision making. Our literature review reveals a gap in this area, as examples such as EVA at risk (Chen, Chau, and Li 2011) or scenarios based on opportunity and threat analysis are not specified (Fontela 1976).

Since research approaches (Figure 1) are not the focus of this article, gaps in this dimension are not specified here.

\subsection{Complementary work}

As user requirements for environmental scanning systems were addressed already in a multi-case study by Mayer (2012), we examine shortcomings regarding the models and methods used. Motivated by sect. 1 , we performed a complementary literature search focusing on the information gathering and interpretation tasks of such systems.

Following vom Brocke, Simons, Niehaves, Riemer, Plattfaut, and Cleven (2009), we analyzed the following six relevant IS journals as determined by both their ranking based on journal rankings of AIS (2010) and VHB (2008) and as well as by their impact factor from http://www.elsevier.com: MIS Quarterly, Decision Support Systems, Information \& Management, Journal of Management Information Systems, European Journal of Information Systems, and Information System Management. Furthermore, we expanded our list with ICIS and ECIS proceedings.

Using EBSCO host, Google Scholar, Science Direct, and Wiley Inter Science, our keyword search for "prediction, forecasting, decision making, environment" and "economic indicator, business indicator, financial indicator, key performance", and "company, business" produced another six relevant publications. Doing a backward and forward search led to twenty-four articles in total (Figure 1).

\subsection{Findings}

A variety of models and methods were proposed as ways to improve companies' environmental scanning. However, they all involve shortcomings.

Models: Companies make substantial strategic errors based on inaccurate forecasts (Kreilkamp 1987). These result from misleading assumptions about the continuity of driving factors and their interrelations (Barnett 1988). As the volatility of the environments of organizations increases, existing models are unable to cope with this problem (Chang, Lai, and Lai 2006). Dealing with emerging risks requires a combination of established and new models, as well as more efficient, unified, and adaptive applications (Leigh, Purvis, and Ragusa 2002). Additionally, systems should incorporate expert knowledge (Barnett 1988), which is especially valuable due to its causal nature (Nadkarni and Shenoy 2004).

Methods: A great deal of data on the environments of companies is available today, but it is often too complex to handle (Garg, Walters, and Priem 2003). Ahn and Ezawa (1997) confirmed that the increasing number of interrelated variables and associated data volumes strongly exacerbate the need for information interpretation, and that knowledge is only "valuable when it is applied appropriately in executive decision making". Qualitative information should complement those areas where data are still scarce (Cowell, Verrall, and Yoon 2007). 


\subsection{Environmental Scanning System Designs Using BNs are Missing}

"Modern" approaches for environmental scanning systems can cope with some of these shortcomings (Kuo and Xue 1998). Often, however, they are unable to handle discontinuities, their findings lack transportability and transparency, and they do not incorporate qualitative information (Olson, Delen, and Meng 2012). Most importantly, they lack a hybrid approach that integrates quantitative information from "classical" mathematical approaches and qualitative expert knowledge.

Several authors (e.g., Lauria and Duchessi 2006; Sun and Shenoy 2007) argued for BNs to handle these challenges of a hybrid combination. Thus, we propose their application to improve environmental scanning systems with indicator-based information gathering and interpretation.

BNs make it possible to represent complex data using a directed acyclic graph and corresponding conditional probability tables for each network variable, encoding a joint probability distribution based on multiplicative factorization (Ben-Gal 2007). Because BNs are comprehensive and descriptive, they are easy to interpret for users (Sun and Shenoy 2007). They are also able to model causal relationships and combine quantitative data with qualitative information (Nadkarni and Shenoy 2004). Furthermore, BNs enable reasoning under uncertainty for inferential tasks, such as classification, prediction, or diagnosis (Lauria and $\mathrm{Du}-$ chessi 2006).

However, the literature lacks comprehensive descriptions of the data elicitation and interpretation processes for BNs. This exhibits the need for more granular, but ready-to-use manuals to make BNs applicable for environmental scanning systems in practice.

\section{Applying BNs for Environmental Scanning Systems}

March and Smith (1995) defined four DSR products: constructs, models, methods, and instantiations. Constructs describe the underlying phenomena, models combine constructs into an IS artifact, methods are goal-oriented and translate the model into a problem solution, and instantiations transfer the IS artifact into its environment.

In light of our findings about the shortcomings of environmental scanning systems, we outline a hy- brid process model for handling concrete features, or combinations of these for information gathering and interpretation tasks (Gregor 2006; vom Brocke 2003).

Method engineering (ME) covers several components (for ME in general, Brinkkemper 1996). The most important ones are result, meta model, role, technique, activity, and tool (Gutzwiller 1994). With our to-be-developed hybrid process model we focus on activities to set-up a model that combines quantitative information for environmental scanning systems derived from regression analyses and qualitative knowledge from expert interviews.

\subsection{Indicator Aggregation and Analysis}

In a first step, environmental sectors to be scanned must be defined (Garg, Walters, and Priem 2003). These sectors should embrace the company's strategic program and vision (Yasai-Ardekani and Nystrom 1996), and reflect the value chain (Porter and Millar 1985), e.g., in the industrial sector along the functions of procurement, production, and sales (Day and Schoemaker 2005). Capital supply, research and development, and human resources are additional areas of the internal environment to be considered. The more volatile the company's environment is, the more elements of the external environment should be scanned (Day and Schoemaker 2005).

Next, a comprehensive list of BEIs for the identified scanning areas must be compiled. This list can be based on literature (e.g., Levanon 2010), online resources (e.g., OECD), and internal databases, such as enterprise resource planning (ERP) systems. As BEIs serve as explanatory variables, it is necessary to determine those most appropriate for forecasting each key financial to be explained. We propose evaluating BEIs in terms of their presumable relevance for and causal connection to the company's financial performance.

Utilizing historical data, regression analyses determine causal relationships between a set of regressors and the regressand. We propose a multiple linear regression analysis to identify BEIs and time lags that explain suitable variations in a company's key financial. This can be accomplished by performing a regression analysis for each possible combination of indicators and time lags.

The number of possible models is limited by defining a maximum regressor group size, based on the increasing efficiency and decreasing complexity of 
scanning activities with decreasing number of monitored indicators. Moreover, time lag variability is limited due to the size of the data set and requisite time to derive strategic measures from provided insights as well as data publication delays.

The resulting regression models should be analyzed not only for fit (adjusted $\mathrm{R}^{2}$ ) and regressor significance (t-test and F-test), but also for multicollinearity, autocorrelation and their forecast accuracy. Suitable models using these parameters should be qualitatively evaluated through experts. Such evaluation can cover relevant environmental areas as well as the explicability of positive or negative coefficients.

\subsection{Regression-Based Network}

Given a directed, acyclic graph $\mathrm{G}[\mathrm{V}, \mathrm{E}]$ with discrete probability variables $\mathrm{U}=\left[\mathrm{A}_{1}, \ldots, \mathrm{A}_{\mathrm{n}}\right]$, represented as $\mathrm{V}$ and connected by edges $\mathrm{E}$, and conditional probability distributions $\mathrm{P}\left(\mathrm{A}_{\mathrm{i}} \mid \mathrm{pa}\left(\mathrm{A}_{\mathrm{i}}\right)\right)$ for each $\mathrm{A}_{\mathrm{i}}$ in $\mathrm{U}$, a $\mathrm{BN}$ encodes a joint probability distribution for the problem through multiplicative factorization:

(1) $\mathrm{P}(\mathcal{U})=\mathrm{P}\left(\mathrm{A}_{1}, \ldots, \mathrm{A}_{\mathrm{n}}\right)=\prod_{\mathrm{i}=1}^{\mathrm{n}} \mathrm{P}\left(\mathrm{A}_{\mathrm{i}} \mid \mathrm{pa}\left(\mathrm{A}_{\mathrm{i}}\right)\right)$

BNs, as a subclass of probabilistic graphical models, allow abductive, deductive, and intercausal inferences under uncertainty. Moreover, the flow of information depends on the type of nodal connection involved, differentiating serial, converging, or diverging connections. Figure 2 shows an example for a product launch problem domain.

The chain rule for BNs defined above leads to the joint probability distribution $\mathrm{P}(\mathrm{R}, \mathrm{C}, \mathrm{D}, \mathrm{L})$, which, in turn, can be utilized to make an inverse inference about the probability of a market leadership position, given evidence about a high product launch rate: $\mathrm{P}(\mathrm{L}=$ leader $\mid \mathrm{R}=$ high $)$.

For our environmental scanning model, the set of indicators and corresponding time lags must be transformed into a BN. An intuitive way to accomplish this is to define the BEIs as parent nodes with directed links to the key financial as child node. Furthermore, as data requirements grow exponentially with the number of states (Sarkar and Sriram 2001) and separation into more than three states lowers performance (Sun and Shenoy 2007), variable data should be split into two or three ranges, e.g., based on positive vs. negative period-on-period growth. BNs can handle discrete as well as continuous variables, but coping with the latter requires determining the variables' density functions and underlying distributions (Jensen and Nielsen 2007), and the benefits from such an elaborate approach are questionable (Sun and Shenoy 2007).

Finally, conditional probability tables (CPTs) must be determined for the BN. Assuming the network structure is known, maximum likelihood estimation or the expectation maximization algorithm should be applied (Ben-Gal 2007).

\subsection{Knowledge-Based Network}

While explicit knowledge can be measured with management and accounting tools such as balanced scorecards (Kaplan and Norton 1992), handling tacit knowledge is more complex (Spender and Marr 2005). As such knowledge is primarily held by individuals, experts are a critical resource for an organization (Abraham, Saulquin, and Soparnot 2011). Their knowledge can be elicited through interviews, which are a powerful, qualitative tool in IS research (Myers and Newman 2007).

Figure 2: BN for a product launch (adapted from Nadkarni and Shenoy 2001)

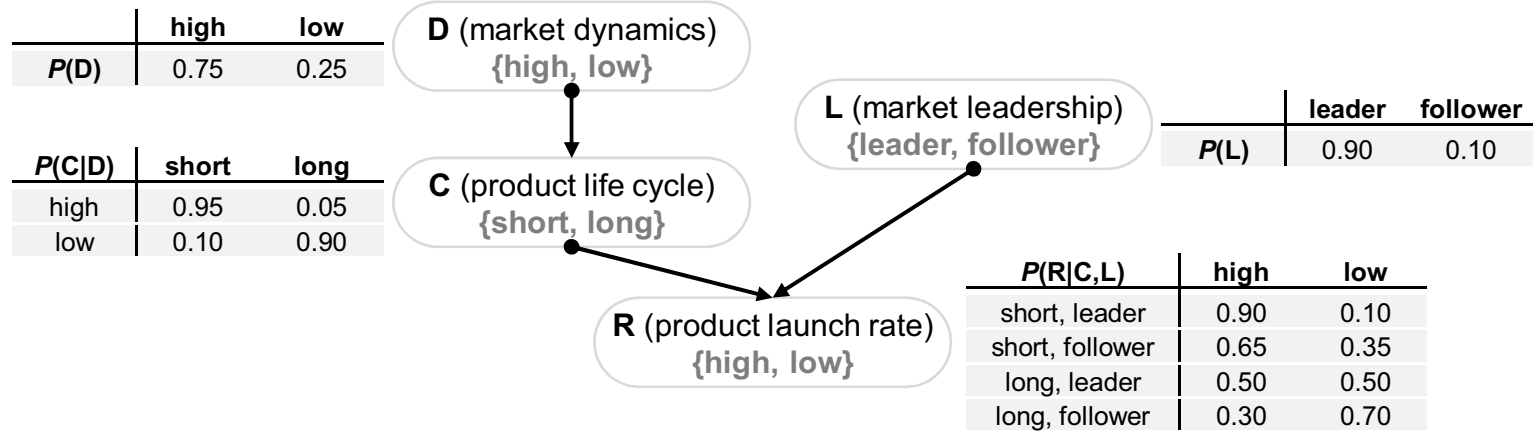


Because BNs with knowledge-based structures and quantifiable variables are the most effective (Nadkarni and Shenoy 2004), we propose using expert interviews to arrive at knowledge-based network structures. In doing so, semi-structured approaches have an exploratory character and produce a rich understanding of the individual's expertise and reasoning processes (Nadkarni and Shenoy 2004). Face-to-face interviews increase the willingness of interviewees to disclose detailed information and help prevent misunderstandings (Kornmeier 2007). Interviewees with expertise, which we define as informed intuition beyond rule-based systems in the determined scanning areas (Dreyfus and Dreyfus 2005; Ericsson, Prietula, and Cokely 2007), must be identified. The benefit of multiple individual interviews are decreasing average biases and synergy effects from complementary areas of expertise, which lead to broader and deeper insights than an individual expert can provide (DiCicco-Bloom and Crabtree 2006; Nadkarni and Nah 2003).

Interviews utilizing in-depth, open-ended questions with probes are most effective (Nadkarni and Nah 2003). Thus, the interview should start with a question such as: "What factors would you consider to have a relevant impact on this company's revenues?" and the interviewer should probe each mentioned factor to explore related variables, causeeffect chains, and estimated time lags for each directed link. The findings should be mapped du- ring the interview to enable immediate reflection. Lists of BEIs for each environmental area can support the experts' reasoning processes. Moreover, collaboration with interviewees and perceived support for creativity will further enhance the exploration of experts' creative potential (Diliello, Houghton, and Dawley 2011).

This interview approach results in multiple BNs that must be aggregated. The literature mentions matrix algebra (Nadkarni and Nah 2003) or web-based Delphi methods (Scavarda, Bouzdine-Chameeva, Goldstein, Hays, and Hill 2006) as ways to perform this aggregation, but fails to specify how to do integrate expert knowledge (Cinar and Kayakutlu 2010; Li, Wang, Leung, and Jiang 2010). While group dynamics can lead to biases, group processes and interaction can also enhance collaborative learning (Nadkarni and Nah 2003). Therefore, we propose a collaborative workshop with the interviewed experts to arrive at a group consensus on BNs with characteristic BEIs (Sundstrom, Busby, and Bobrow 1997).

Participants' key behaviors for such group problemsolving, which should be managed by the instructor, are as follows: discussing problem-solving strategies; inviting members to express their task-related ideas or knowledge; and identifying and summarizing points of agreement and disagreement (Sundstrom, Busby, and Bobrow 1997).

\section{Figure 3: Network structure of the hybrid scanning model}

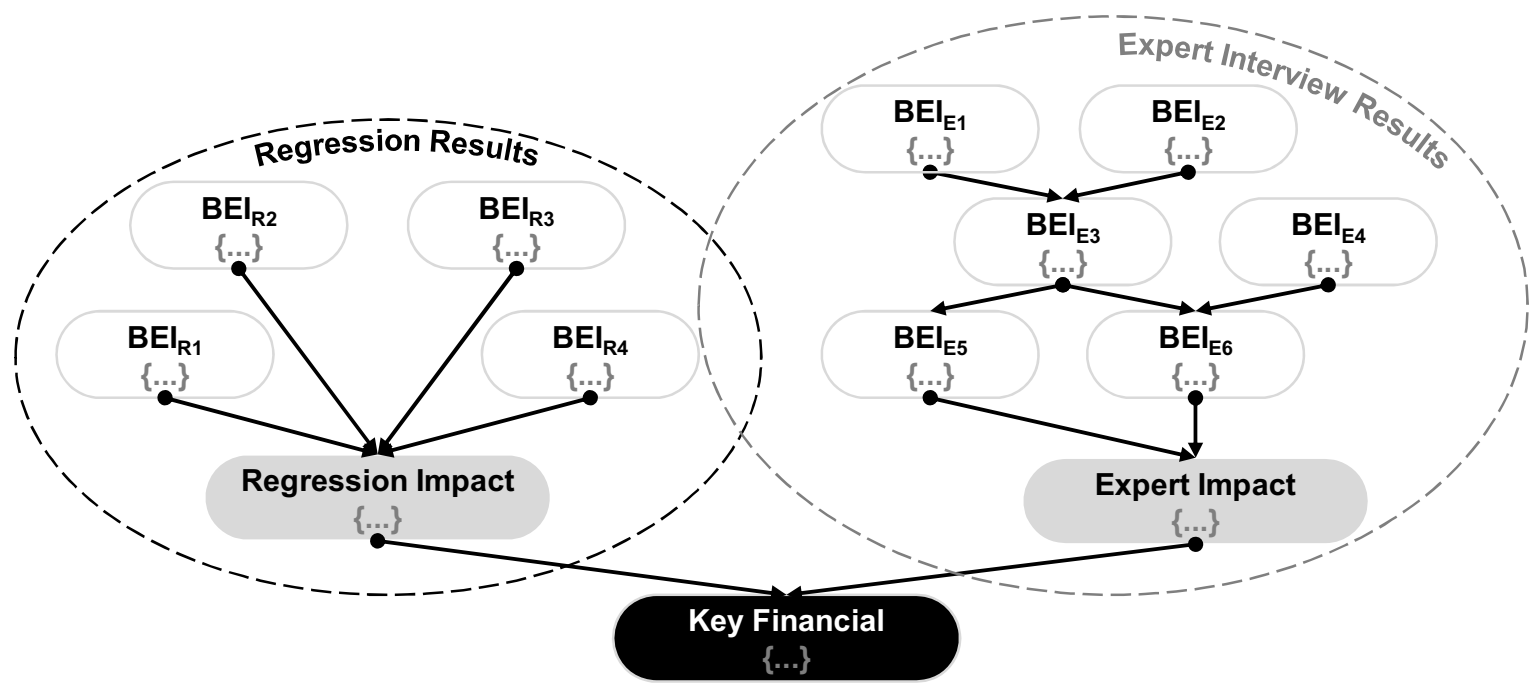


As this approach focuses on quantitative BEIs, the BEIs included in the final network should be based on accessible data to enable the calculation of probabilities based on historical trends. For variables where data access is scarce, probabilities can alternatively be determined from experts through probability encoding techniques (Bielza, Gomez, and Shenoy 2010).

\subsection{Network Integration}

In summary, the process model results in two BN alternatives: One derived from data using multiple regression analysis and the other assessed qualitatively from expert knowledge. Since regression analysis is applied to identify the combination of indicators and time lags with the highest explanatory power, changing the selection of variables would not only invalidate the determined statistical measures for this network, but also inevitably result in a less significant model, because this alternative set of variables has already been accounted for during the analysis and evaluation process. Therefore, the integration of expert knowledge into the data-based BN must not induce a modification or extension of the regression model's variable structure.

Instead, we propose a combination of quantitative and qualitative results by allocating the model alternatives to individual clusters, where each cluster interrelates with a mediating variable, which, in turn, comprise the only two parent variables of the key financial. The resulting, fully integrated hybrid BN structure is illustrated in Figure 3.

The transformation can be accomplished through parent divorcing (Jensen and Nielsen 2007), which requires additional information about the relationship of the intermediate variables and the key financial. This prerequisite can be utilized as a lever to regulate the impact of the statistical versus the qualitative cluster, and thus enables adaptability according to the user's confidence in quantitative versus qualitative models. The subsequent calculation of CPTs should be supported by IT-based tools such as HUGIN (Hugin Expert A/S) or Netica (Norsys Software Corp.) for commercial software; or freeware tools including GeNie\&SMILE (Decision Systems Laboratory) and Belief and Decision Networks (AIspace). While the CPTs are continuously updated with new data, retrospective controls should regularly verify or revise the network struc- ture of the environmental scanning model as more knowledge is gained.

The resulting hybrid model has two central capabilities: On the one hand, it can be utilized to forecast the development of the key financial in terms of discrete states as more data on the BEIs become available. On the other, the development process of the scanning model, especially the interactive interviews and workshop, contribute to a collective learning experience and should thus improve the acceptance of environmental scanning systems in general.

\section{Case Study}

Case studies enable researchers to learn from practice and understand complex processes by studying IS in natural settings (Benbasat, Goldstein, and Mead 1987). With a single case study, we evaluated the utility of our model. We did that with a particular focus on learning about applying BNs in practice. Case studies increase the persuasiveness of findings, in particular because they examine real-life situations and consider their specific context, i.e. the situation in which activities take place; build on people's experiences and practices; provide in-depth information; and recognize the complexity and embeddedness of activities (Yin 2009).

\subsection{Company and Project Background}

The company operates in the power technology and industrial automation industries. It has a diverse portfolio ranging from short-cycle products, such as light switches, to long-cycle products, such as transformers and control systems for entire power networks. In 2011, the company reported revenues of around USD 40bn and employed over 130,000 people in more than 100 countries.

To improve the companies' environmental scanning system, the Group Controlling and Planning Department set up a project - the "new corporate radar." Aligning upcoming business requirements with corporate IS capabilities, the project's objective was to predict group base orders with suitable BEIs to support a more fact-driven executive decisionmaking. We specify "suitable" in terms of a comprehensive set of BEIs from the content perspective, but condensed in terms of information presentation. Current approaches comprised a model based on estimates of the gross domestic product (GDP), limited to predictions of economic development on 


\begin{tabular}{|c|c|c|c|c|c|c|}
\hline Name & Intercept & $\mathrm{CCl}$ & CLI & PMI & MPI & PIR \\
\hline Time Lag & - & 8 & 8 & 8 & 8 & 8 \\
\hline Coefficient & |-1091.67 & 8.77 & 1.91 & 1.07 & -0.50 & 0.66 \\
\hline $\mathrm{t}$-Value & 5.58 & 4.37 & 3.56 & 3.02 & 3.66 & 3.67 \\
\hline $\mathrm{p}$-Value $(\mathrm{t})$ & 0.00 & 0.00 & 0.01 & 0.00 & 0.00 & 0.00 \\
\hline Adj. $R^{2}$ & 0.77 & \multirow[t]{3}{*}{ Formula: } & \multirow{3}{*}{\multicolumn{4}{|c|}{$\begin{array}{l}B O_{t}=-1091.67+8.77 C C I_{t-8}+1.91 C L I_{t-8} \\
\quad+1.07 P M I_{t-8}-0.50 M P I_{t-8}+0.66 P I R_{t-8}\end{array}$}} \\
\hline$p$-Value $(F)$ & 0.00 & & & & & \\
\hline MAPE & 0.04 & & & & & \\
\hline
\end{tabular}

annual basis. Moreover, management reports contained little information about the company's environment and there was a lack of standardized tracking of external indicators. Since environmental scanning efforts in the company mainly focused on the internal perspective and lacked a systematic approach as well, the project aimed at transferring knowledge from research to practice to establish a more comprehensive environmental scanning model, focusing on the general economic and the task environment. The latter covers customers, suppliers, competitors, and regulatory bodies. The authors participated as external experts.

\subsection{Results}

The diversity of its product offering means the company's "typical" key financials, such as net sales or EBIT (earnings before interest and taxes), are volatile. Thus, base orders were chosen to be predicted variable. This indicator is defined as the organic demand for orders below USD $15 \mathrm{~m}$.

Regression-based network: With findings from desk research (sect. 5.2), a list of more than 100 BEIs was compiled. These indicators were evaluated by the project team based on measurement frequency and accessibility of data, as well as contextual and causal fit to identified scanning areas to arrive at the 26 most relevant BEIs. Because some internal information was unavailable, data on indicators covered the period from July 2009 to March 2012 only.

Next, a tool to perform regression analyses was developed in Visual Basic for MS Excel, as required by the company. Based on requirements of potential users of the scanning system, the maximum number of BEIs was limited to six. Time-lag variations were confined to four to twelve months, because data were published with a delay of up to three months and forecasts beyond twelve months were considered unreliable.

Due to MS Excel run time, time lags could not be assigned individually across indicators. Therefore, sets of one to six BEIs with equal time lags of four to twelve months across all explanatory variables were picked from the shortlist and analyzed. This process resulted in 3,766,932 combinations in total. After adjusting the parameter strictness, evaluating coefficients, and performing additional statistical tests (as described in sect. 5.1), the team selected a five-variable model (Figure 4) with time lags of eight months to base orders. This model was identified as the most suitable set of BEIs to predict base orders compared to all alternative sets of five, six or fewer variables, especially based on the high level of fit (adjusted R-squared above 76\%) and forecast accuracy (mean absolute percentage error of $4.4 \%$ ).

In this regression model, the negative coefficient assigned to the MPI was controversially discussed by the experts. This indicator synthesizes several commodity prices, weighted by their usage in the company. As the company and most of its customers are highly exposed to commodity price movements, the explanation for the negative relationship was as follows: A falling material price reduces production costs and could trigger lower target 
pricing of products, which could increase orders. In turn, some experts argued that increasing material prices indicate an overall growth of price levels, which exposes increasing prosperity in the long run and would thus explain a positive coefficient. The final regression model was transformed into a $\mathrm{BN}$ through the experts via discretization of the BEIs (two states: positive/negative) and the key financial (three states: less than $/+2 \%$ to $-2 \% /$ more than) based on month-on-month growth rates.

Knowledge-based network: For the second dimension of our model, one-to-one interviews were conducted (sect. 5.3). Three experts from the Group Planning and Controlling Department were asked to answer open-ended questions and corresponding probes. This is just a small number of interviews; however, it enables us to elicit expert knowledge from senior managers who are scarce in time. The resulting insights were illustrated on a whiteboard. To explore their knowledge further, the experts also discussed the scanning sectors that had been identified, as well as the 26 shortlisted BEIs (sect. 6.1). Finally, the experts were asked to estimate time lags from parent nodes to child nodes for each directed link. The interviews lasted 45 minutes. In a second step, all three experts where invited to a consensus-driven workshop, where each expert explained his/her perspective. The moderator facilitated an interactive discussion to arrive at a consensus-based solution. The workshop lasted 60 minutes. Figure 5 illustrates the final network structure, in which three key points are worth discussing:

(1) As division A focuses on mass products, its shortcycle business is highly sensitive to market developments. Therefore, the experts identified its base orders as a leading indicator for group-level variations. (2) Divisions B and C, in turn, focus on large, project-based products, which depend on factors such as the political and regulatory environment and key account managers. Therefore, their sales are not necessarily linked to market and economic developments. However, their large orders most often trigger subsequent base orders. (3) The variable "critical events," which one of the experts emphasized, is also noteworthy. His argument resulted from skepticism towards mathematical models in environmental scanning. He explained that besides weak signals, critical events, such as major production breakdowns, must always be monitored manually, outside an automated system's boundaries. Therefore, this unquantifiable variable was included in the network structure (Figure 5).

In a last step, the regression-based and knowledgebased findings were combined to form an integrated BN (sect. 5.4). Due to the limited data set at hand, the team was not able to adequately determine CPTs for the integrated BN. Therefore, mathematical linkage of the two clusters and subsequent incorporation into decision-making processes was not accomplished within the case study.

\subsection{Lessons Learned}

The combined application of BNs and "pure" mathematical models increases the acceptance of the latter as well as environmental scanning systems in general. As stated in sect. 6.2, one of the experts identified a need to monitor critical events beyond the model's boundaries. This perspective results from his skepticism on mathematical approaches for environmental scanning and risk management. During the project he assessed BNs as intuitive, understandable and illustrative; he became strongly engaged in the scanning model. Thus, as a first lesson learned from our instantiation is that $\mathrm{BNs}$ increase the acceptance of mathematical models and environmental scanning systems in general among both experts and decision makers. One-to-one interviews in combination with a problem-solving workshop are an expedient approach for reaching consensus among experts. A two-phase approach can cope with the complexity of environmental scanning by first exploring the experts' individual knowledge and then, subsequently, finding consensus in a workshop. Even the experts themselves assessed the interviews as enhancing their individual creativity. They also said the workshop incorporated their perspectives in a balanced way of result finding and, therefore, they evaluated our two-phase approach as a good method for generating reliable findings. From the project team perspective, this approach is pragmatic because it requires little time for preparation and post-processing.

Collaboration and interaction improve intersubjectivity and contribute to organizational knowledge. The interviewed experts liked the collaborative approach. Having multiple experts reflect on the company's external and internal 


\section{Figure 5: Final BN structure assessed from expert knowledge}

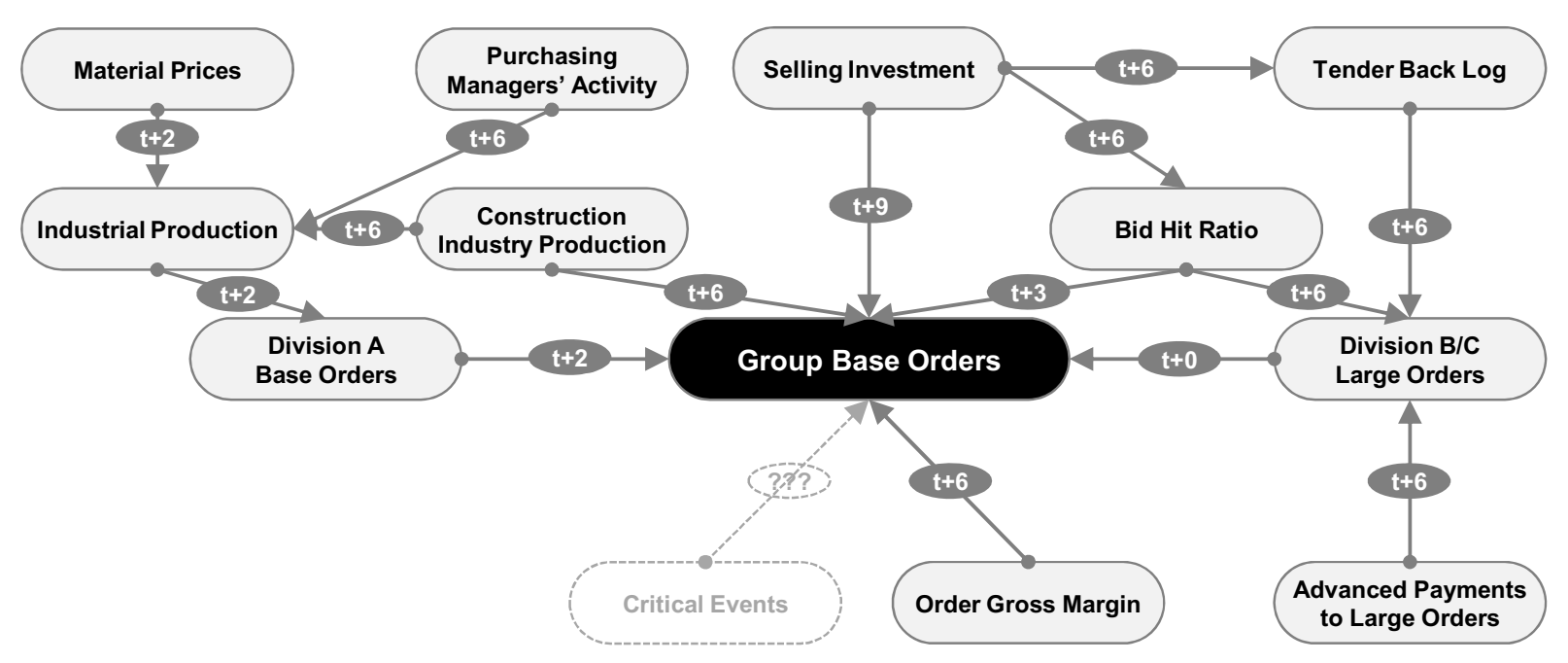

environment and determine the most relevant areas creates valuable insights about the company's strengths, risks, and opportunities. Moreover, it supports both decision makers and knowledge workers in understanding their business. One of the participants stated that he will reflect the BEIs in his future financial planning processes to ensure completeness. The approach described here facilitates intersubjectivity, which improves the efficiency and performance of corporate planning and controlling (Eden, Jones, Sims, and Smithin 1981), as well as potentially any member of the organization provided with the findings.

\section{Evaluation}

In keeping with the objective of this article, we evaluate our hybrid approach's utility. We differentiate between (scientific) rigor and (relevance for practice, Hevner, March, Park, and Ram 2004).

Drawing on concepts from requirements engineering (Sommerville 2007), we specify rigor in terms of completeness and traceability. Relevance, in turn, refers to the criteria of transparency, transportability, and bias prevention (Olson, Delen, and Meng 2012).

Though BNs can also be derived "purely" from mathematical analysis (e.g., Wong and Guo 2008), the application of BNs on hand incorporates expert knowledge into data-based networks and applies quantitative as well as qualitative evaluation processes. Other hybrid approaches successfully introduced to the environmental scanning domain include system dynamics (Lyneis 2000) and agentbased systems (Liu 2000), both of which are computational simulation methods for dynamic problems. System dynamics models problems as stocks and flows with feedback loops that are simulated via differential equations over time (Lane 2000), while agent-based systems simulate interrelations of autonomous agents with intelligent, rule-based behavior (Shirazi and Soroor 2007). Thus, both approaches are based on model assumptions that strongly differ from the more static model using discrete variables on hand making a direct evaluation against our model infeasible. We, therefore, compare our hybrid model with "pure" mathematical models, taking regression analysis and artificial neural networks as our references. In doing so, we applied a five-step rating scale ranging from "very bad" to "very good." The results are summarized in Figure 6.

Completeness: We developed our hybrid model based on findings from literature review. The model supports executives' decision making by integrating quantitative data from regression analysis with qualitative expert knowledge, and also allows nonlinear and multilevel relationships among variables. The fact that the model is restricted to initially fixed 
Figure 6: Evaluation results

\begin{tabular}{|c|c|c|c|}
\hline \multicolumn{2}{|c|}{ Evaluation Criteria } & $\begin{array}{l}\text { „Pure" mathe- } \\
\text { matical models }\end{array}$ & $\begin{array}{l}\text { Hybrid model } \\
\text { on hand }\end{array}$ \\
\hline \multirow{2}{*}{ 흠 } & Completeness & o & ++ \\
\hline & Traceability & o & - \\
\hline \multirow{3}{*}{ 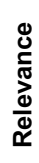 } & Transparency & $\mathbf{0}$ & ++ \\
\hline & Transportability & - & + \\
\hline & Bias prevention & + & $\mathbf{0}$ \\
\hline
\end{tabular}

variables is a limitation, but larger data sets and more efficient regression analysis software can address this drawback. Since our hybrid approach enables both, collective learning and the gathering and interpretation of information, including tacit knowledge, we evaluate its completeness as "very good."

Mathematical models, such as artificial neural networks, are also capable of modeling complex, multilevel variable relationships (Kuo and Xue 1998). Moreover, some approaches rely on expert knowledge, such as to define function hypotheses. However, these qualitative elements are most often limited to explicit information rather than tacit expert knowledge. Furthermore, mathematical models originate from mathematics, engineering, natural science, etc. and are then transferred to environmental scanning, while our hybrid approach was explicitly developed for this task. Therefore, we evaluate such mathematical models as "somewhat" complete.

Traceability reflects whether a comprehensible process leads to the scanning results. Artificial neural networks are black boxes (Olson, Delen, and Meng 2012), thus, we evaluate the traceability of these mathematical models as "very bad." Trend projections (e.g., Merritt 1974) rely exclusively on simple linear functions ("very good" traceability). Therefore, we rank mathematical models "somewhat" traceable in general.

Our hybrid approach applies BNs and regression analysis. BNs are based on basic probability theorems and intuitive modeling techniques ("good" traceability). Multiple regression analyses and related test procedures, in turn, require advanced statistical knowledge and experience ("bad" traceability). However, the fact that the hybrid approach combines two models complicates traceability, which we therefore evaluate "bad."
Transparency describes the intelligibility of the model's results for users. Based on findings from our literature review and the lessons learned from the case study, BNs are illustrative and easy for users to interpret. They enable a good understanding of complex relationships between a company's environment and its financial performance. When the learning algorithm identifies a variable as suitable while the expert knowledge does not concur (or vice versa), contradiction of information seems to be a valid concern. We evaluate the handling of these special cases as strength of our proposed model. When variables appear in both, the regressionbased and knowledge-based network, it emphasizes the exposed importance of these BEIs for environmental scanning and they are thus given a higher weight in the hybrid model. When variables appear in only one of the networks, it ensures the comprehensiveness of the scanning activities - combining expert knowledge with quantitative information, but attributes these BEIs a lower weight. Thus, we evaluate hybrid models as "very transparent."

Mathematical models, in turn, most often produce single data points, such as forecasts for key financials, which are quite intuitive to interpret. However, they do not provide deeper insights into a company's environment or the impact of particular scanning sectors on key financials. Understanding the results of statistical tests requires profound knowledge of the procedures applied. We evaluate mathematical models as "somewhat" transparent. Transportability refers to the ability to use the model in diverse settings. Because it individually defines the relevant scanning sectors and BEIs, the hybrid approach can be adapted for different types of organizations. More importantly, this model allows flexible weighting of quantitative and qualitative findings. Therefore, it can be adjusted to different user preferences, leading to high user acceptance. We evaluate the transportability of findings from our hybrid approach as "very good."

Mathematical models, in turn, are restricted to a particular field of application or are only designed for specific sets of data. For this reason, we evaluate their transportability as "bad."

Bias prevention refers to how well the model eliminates subjectivity. Mathematical approaches apply algorithms or static functional relationships and thus produce objective results. However, many of these models involve a selection of variables or function hypotheses driven by individuals. There- 
fore, they are only evaluated as "good" at preventing bias. The hybrid approach also relies on the initial selection of BEIs, and the involvement of several experts and their knowledge brings the risk of subjectivity. However, the structured, rule-based combination of quantitative and qualitative models as well as the application of established research methods helps to manage this challenge. Furthermore, the various perspectives of the interviewed experts are aligned in a workshop (sect. 6.3). We assess the level of bias prevention our hybrid approach offers as "somewhat."

Summarizing the evaluation, we propose that the hybrid model described here outperforms mathematical models, especially by leveraging BNs to integrate qualitative expert knowledge.

\section{Conclusion, Limitations, and Future Research}

Much work has been done on environmental scanning systems since Ansoff (1975). To manage companies' volatile environment, we proposed a hybrid model for the information gathering and interpretation tasks of environmental scanning systems. Our model combines quantitative information derived from regression analyses and qualitative knowledge from expert interviews, and integrates the findings in a $\mathrm{BN}$. We demonstrated the utility of this approach with a first instantiation. Our work contributes to research by complementing the body of knowledge on managing companies' environment. Moreover, we introduced BNs to a new and promising IS domain: environmental scanning systems. For practitioners, we offer a new, multi-faceted model. In particular, its flexibility to accommodate different user preferences should improve environmental scanning system acceptance.
Our research reveals several avenues for future research. The literature review should be expanded with practitioner publications to include more findings from environmental scanning systems in dayto-day business. However, this should be a secondary issue. Because case studies do not lead to a strong understanding of how often phenomena occur in a total population and, thus, do not allow for generalizability, a next design cycle should include more instantiations within a multi-case study and, even better, a broader empirical analysis to improve the shortcoming of our first instantiation on hand.

Our hybrid model is restricted to a limited set of tobe-analyzed BEIs from the beginning (sect. 5.1), the qualitative evaluation of the findings from regression analyses (sect. 6.2) and a rather small group of interviewed experts (sect. 6.2). Future research could expand our approach with a broader analysis of BEIs, additional regression function hypotheses, a larger number of interviewees and further statistical tests.

Calculating CPTs represents another challenge, as it requires large data sets that grow exponentially with the number of direct parent nodes of the key financial (Sanford and Moosa 2012). This became evident in the case study, because it was not possible to calculate the CPTs for the networks based on the limited data set (sect. 5.2). Moreover, contradictory information about the relevance of BEIs (sect. 7) could be of concern when calculating CPTs. Therefore, the design of subsequent reporting to executives should be part of a next study.

These shortcomings mean that, so far, it is not possible to determine for sure whether our findings lead to more applicable environmental scanning systems. However, the findings should provide concrete starting points for future research. 


\section{Appendix: List of Business Environment Indicators after first screening}

The following table contains the 26 most relevant BEIs as determined by the project team (sect. 6.2, p. 8). The indicators constituting the final selected, five-variable model (sect. 6.2, p. 9; Figure 4) and the independent, to be predicted variable (base orders) are highlighted.

\begin{tabular}{|c|c|c|c|c|c|}
\hline No. & Abbr. & Source & Name & Unit & Description \\
\hline $\mathbf{1}$ & $\mathrm{AL}$ & Bloomberg & $\begin{array}{l}\text { Aluminum } \\
\text { Price }\end{array}$ & USD per metric ton & Cash settle price for aluminum at the London Metal Exchange. \\
\hline 2 & BCI & OECD & $\begin{array}{l}\text { Business } \\
\text { Confidence } \\
\text { Indicator }\end{array}$ & $\begin{array}{l}\text { Index, long-term } \\
\text { average = 100, } \\
\text { standardized, } \\
\text { amplitude adjusted, } \\
\text { seasonal adjusted }\end{array}$ & $\begin{array}{l}\text { Standardized confidence indicator based on careful selection of } \\
\text { national indicators; smoothed, centered and amplitude } \\
\text { adjusted time series. For the majority of countries, calculated } \\
\text { from harmonized industrial confidence indicators. Only } \\
\text { representing the manufacturing sector, as data availability for } \\
\text { other sectors is scarce. }\end{array}$ \\
\hline 3 & BDI & $\begin{array}{l}\text { IHS Global } \\
\text { Insight }\end{array}$ & $\begin{array}{l}\text { Baltic Dry } \\
\text { Index }\end{array}$ & $\begin{array}{l}\text { Index } 1985-01-04= \\
\text { 100, monthly } \\
\text { average }\end{array}$ & $\begin{array}{l}\text { Shipping and trade index composed by three sub-indexes } \\
\text { based on different dry bulk carrier sizes, created by the } \\
\text { London-based Baltic Exchange. Measures changes in the cost } \\
\text { to transport raw materials such as metals and fossil fuels by } \\
\text { sea, based on direct assessment by shipping brokers. }\end{array}$ \\
\hline 4 & $\mathrm{CCI}$ & OECD & $\begin{array}{l}\text { Consumer } \\
\text { Confidence } \\
\text { Indicator }\end{array}$ & $\begin{array}{l}\text { Index, long-term } \\
\text { average = 10o, } \\
\text { standardized, } \\
\text { amplitude adjusted, } \\
\text { seasonal adjusted }\end{array}$ & $\begin{array}{l}\text { National consumer confidence indicator; smoothed, centered } \\
\text { and amplitude adjusted time series. }\end{array}$ \\
\hline 5 & CLI & OECD & $\begin{array}{l}\text { Composite } \\
\text { Leading } \\
\text { Indicator }\end{array}$ & $\begin{array}{l}\text { Index, trend } \\
\text { restored }\end{array}$ & $\begin{array}{l}\text { Time series formed by aggregating a variety of component } \\
\text { indicators which show a reasonably consistent relationship } \\
\text { with a reference series (e.g., GDP) at turning points. Designed } \\
\text { to provide qualitative information on short-term economic } \\
\text { movements, especially at turning points, with average lead } \\
\text { times of four to eight months. }\end{array}$ \\
\hline 6 & CPI & $\begin{array}{l}\text { IHS Global } \\
\text { Insight }\end{array}$ & $\begin{array}{l}\text { Consumer Price } \\
\text { Index }\end{array}$ & $\begin{array}{l}\text { Percent, month-on- } \\
\text { month change }\end{array}$ & $\begin{array}{l}\text { Examines the weighted average of prices of a basket of } \\
\text { consumer goods and services, calculated by weighted average } \\
\text { of price changes of these goods based on importance. Changes } \\
\text { in consumer prices are associated with the cost of living. }\end{array}$ \\
\hline 7 & $\mathrm{CU}$ & Bloomberg & Copper Price & USD per metric ton & Cash settle price for copper at the London Metal Exchange. \\
\hline 8 & EEI & ZEW & $\begin{array}{l}\text { Economic } \\
\text { Expectations } \\
\text { (by industry) }\end{array}$ & Scale, $\mathrm{o}=$ balance & $\begin{array}{l}\text { Indicator of economic sentiment based on a monthly survey of } \\
\text { up to } 350 \text { financial experts. Reflects the difference between the } \\
\text { share of analysts that are optimistic and the share of analysts } \\
\text { that are pessimistic for the expected economic development in } \\
\text { six months. Covers the Eurozone and six individual countries } \\
\text { as well as } 13 \text { industries. }\end{array}$ \\
\hline 9 & EER & ZEW & $\begin{array}{l}\text { Economic } \\
\text { Expectations } \\
\text { (by region) }\end{array}$ & Scale, $\mathrm{O}=$ balance & See EEI \\
\hline 10 & EUEX & Eurostat & $\begin{array}{l}\text { Europe EU27 } \\
\text { Exports (by } \\
\text { destination) }\end{array}$ & $\begin{array}{l}\text { EUR, trade value, } \\
\text { seasonal adjusted, } \\
\text { work day adjusted }\end{array}$ & $\begin{array}{l}\text { Time series values the EU-27 international trade in goods with } \\
\text { the rest of the world. }\end{array}$ \\
\hline 11 & GDP & OECD & $\begin{array}{l}\text { Gross Domestic } \\
\text { Product }\end{array}$ & $\begin{array}{l}\text { Index, } 2005=100 \text {, } \\
\text { seasonal adjusted, } \\
\text { trend }\end{array}$ & $\begin{array}{l}\text { Indicator reflecting the market value of all officially recognized } \\
\text { final goods and services produced within a country in a given } \\
\text { period of time. }\end{array}$ \\
\hline 12 & IP & OECD & $\begin{array}{l}\text { Industrial } \\
\text { Production }\end{array}$ & Index, $2005=100$ & $\begin{array}{l}\text { Volume of output generated by industrial sector production } \\
\text { units. Time series presents changes over time, seasonally } \\
\text { adjusted and indexed.* }\end{array}$ \\
\hline
\end{tabular}




\section{Appendix continued}

\begin{tabular}{|c|c|c|c|c|c|}
\hline No. & Abbr. & Source & Name & Unit & Description \\
\hline 13 & IRSL & $\begin{array}{l}\text { IHS Global } \\
\text { Insight }\end{array}$ & $\begin{array}{l}\text { Interest Rate } \\
\text { Spread (over } \\
\text { U.S., long term) }\end{array}$ & Percent, nominal & $\begin{array}{l}\text { Spread of long-term interest rates over United States treasury } \\
\text { bonds. }\end{array}$ \\
\hline 14 & MEX & $\begin{array}{l}\text { IHS Global } \\
\text { Insight }\end{array}$ & $\begin{array}{l}\text { Merchandise } \\
\text { Exports }\end{array}$ & $\begin{array}{l}\text { USD, seasonal } \\
\text { adjusted }\end{array}$ & $\begin{array}{l}\text { Value of (free on board) goods provided by an individual } \\
\text { country to the rest of the world. }\end{array}$ \\
\hline 15 & MIM & $\begin{array}{l}\text { IHS Global } \\
\text { Insight }\end{array}$ & $\begin{array}{l}\text { Merchandise } \\
\text { Imports }\end{array}$ & $\begin{array}{l}\text { USD, seasonal } \\
\text { adjusted }\end{array}$ & $\begin{array}{l}\text { Value of (cost, insurance and freight) goods received from the } \\
\text { rest of the world by an individual country. }\end{array}$ \\
\hline 16 & MPI & Bloomberg & $\begin{array}{l}\text { Material Price } \\
\text { Index }\end{array}$ & $\begin{array}{l}\text { Index, base month = } \\
100\end{array}$ & $\begin{array}{l}\text { Weighted average of commodity prices based on their } \\
\text { relevance to the company. Specified and calculated for the } \\
\text { purpose of the project. }\end{array}$ \\
\hline 17 & NM1 & OECD & $\begin{array}{l}\text { Narrow Money } \\
\text { (M1) }\end{array}$ & $\begin{array}{l}\text { Index, } 2005=100 \\
\text { seasonal adjusted }\end{array}$ & $\begin{array}{l}\text { Money supply in the form of physical coins and currency along } \\
\text { with demand deposits and other liquid assets held by the } \\
\text { central bank. }\end{array}$ \\
\hline 18 & PIR & $\begin{array}{l}\text { IHS Global } \\
\text { Insight }\end{array}$ & $\begin{array}{l}\text { Policy Interest } \\
\text { Rate }\end{array}$ & Percent, nominal & Interest rate set by central banks based on monetary policy. \\
\hline 19 & PMI & Markit & $\begin{array}{l}\text { Purchasing } \\
\text { Managers' } \\
\text { Index }\end{array}$ & $\begin{array}{l}\text { Index, } 50=\text { no } \\
\text { change to previous } \\
\text { month }\end{array}$ & $\begin{array}{l}\text { Sentiment indicator based on a survey of purchasing managers } \\
\text { in the manufacturing industry, covering production level, new } \\
\text { orders, supplier deliveries, inventories and employment level. }\end{array}$ \\
\hline 20 & PPI & $\begin{array}{l}\text { IHS Global } \\
\text { Insight }\end{array}$ & $\begin{array}{l}\text { Producer Price } \\
\text { Index }\end{array}$ & $\begin{array}{l}\text { Percent, month-on- } \\
\text { month change }\end{array}$ & $\begin{array}{l}\text { Time series measuring the average change in selling prices as } \\
\text { received by domestic producers of goods and services over } \\
\text { time. }\end{array}$ \\
\hline 21 & PTC & OECD & $\begin{array}{l}\text { Production } \\
\text { of Total } \\
\text { Construction }\end{array}$ & $\begin{array}{l}\text { Index, } 2005=100 \\
\text { seasonal adjusted }\end{array}$ & $\begin{array}{l}\text { Volume of output generated by construction sector production } \\
\text { units. Time series presents changes over time, seasonally } \\
\text { adjusted and indexed. }\end{array}$ \\
\hline 22 & PTI & OECD & $\begin{array}{l}\text { Production of } \\
\text { Total Industry }\end{array}$ & $\begin{array}{l}\text { Index, } 2005=100 \\
\text { seasonal adjusted }\end{array}$ & $\begin{array}{l}\text { Volume of output generated by industrial sector production } \\
\text { units. Time series presents changes over time, seasonally } \\
\text { adjusted and indexed.* }\end{array}$ \\
\hline 23 & $\mathrm{SP} 5$ & Bloomberg & $\begin{array}{l}\text { S\&P } 500 \text { Stock } \\
\text { Index }\end{array}$ & $\begin{array}{l}\text { Index, monthly } \\
\text { average }\end{array}$ & $\begin{array}{l}\text { Stock market performance of Standard \& Poor's value } \\
\text { weighted index of largest } 500 \text { firms. }\end{array}$ \\
\hline 24 & ST & Bloomberg & $\begin{array}{l}\text { Hot-Rolled Coil } \\
\text { Steel Price }\end{array}$ & USD per metric ton & 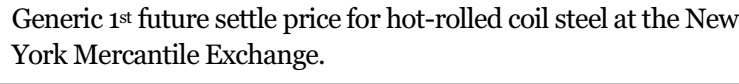 \\
\hline 25 & UER & $\begin{array}{l}\text { IHS Global } \\
\text { Insight }\end{array}$ & $\begin{array}{l}\text { Unemployment } \\
\text { Rate }\end{array}$ & Percent, nominal & $\begin{array}{l}\text { Percentage of the total labor force that is unemployed but is } \\
\text { actively seeking employment and willing to work. }\end{array}$ \\
\hline 26 & WTI & Bloomberg & $\begin{array}{l}\text { Western Texas } \\
\text { Intermediate } \\
\text { Oil Price }\end{array}$ & USD per oil barrel & 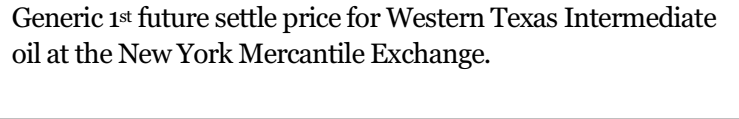 \\
\hline & BO & $\begin{array}{l}\text { Internal } \\
\text { data }\end{array}$ & Base Orders & USD & $\begin{array}{l}\text { To-be-predicted, dependent variable. Organic demand orders } \\
\text { below USD } 15 \mathrm{mn} \text {, excluding recent acquisitions. }\end{array}$ \\
\hline
\end{tabular}

* The two industrial production indicators differ in data composition and computing method and were, therefore, both analyzed. 


\section{References}

Aaker, David A. (1983): Organizing a Strategic Information Scanning System, California Management Review, 25 (2): 76-83.

Abraham, Jocelyne, Jean-Yves Saulquin, and Richard Soparnot (2011): Evaluation of the Value of Experts to a Business: Proposal of a Theoretical Model, Problems and Perspectives in Management, 9 (3): 122-130.

Aguilar, Francis J. (1967): Scanning the Business Environment, Macmillan: New York, NY.

Ahn, Jae-Hyeon and Kazuo J. Ezawa (1997): Decision Support for Real-Time Telemarketing Operations Through Bayesian Network Learning, Decision Support Systems, 21 (1): 17-27.

AIS (2010): MIS Journal Rankings, http://ais.affiniscape. com/displaycommon.cfm?an $=1 \&$ subarticlenbr $=432$ (Access date: 2010-11-20).

Ansoff, Harry I. (1975): Managing Strategic Surprise by Response to Weak Signals, California Management Review, 18 (2): 21-33.

Ansoff, Harry I. (1980): Strategic Issue Management, Strategic Management Journal, 1 (2): 131-148.

Barnett, F. William (1988): Four Steps to Forecast Total Market Demand, Harvard Business Review, 66 (4): 28-38.

Baskerville, Richard (2012): Reviving the IT in the IS, European Journal of Information Systems, 21 (6): 587-591.

Ben-Gal, Irad (2007): Bayesian Networks, in: Fabrizio Ruggeri, Ron S. Kenett, and Frederick W. Faltin (eds.): Encyclopedia of Statistics in Quality and Reliability, Wiley: Chichester, UK, 179184.

Benbasat, Izak, David K. Goldstein, and Melissa Mead (1987): The Case Research Strategy in Studies of Information Systems, MIS Quartely, 11 (3): 369-386.

Bielza, Concha, Manuel Gomez, and Prakash P. Shenoy (2010): Modeling Challenges with Influence Diagrams: Constructing Probability and Utility Models, Decision Support Systems, 49 (4): 354-364.

Boehm, Ernst A. and Peter M. Summers (1999): Analyzing and Forecasting Business Cycles with the Aid of Economic Indicators, International Journal of Management Reviews, 1 (3): 245-277.

Brinkkemper, Sjaak (1996): Method Engineering: Engineering of Information Systems Development Methods and Tools, Journal of Information and Software Technology, 38 (4): 275-280.

Chang, Pei-Chann, Chien-Yuan Lai, and K. Robert Lai (2006): A Hybrid System by Evolving Case-Based Reasoning with Genetic Algorithm in Wholesaler's Returning Book Forecasting, Decision Support Systems, 42 (3): 1715-1729.

Chen, Hsinchun, Michael Chau, and Shu-Hsing Li (2011): Enterprise Risk and Security Management: Data, Text and Web Mining, Decision Support Systems, 50 (4): 649-650.

Choudhury, Vivek and Jeffrey L. Sampler (1997): Information Specificity and Environmental Scanning: An Economic Perspective, MIS Quarterly, 21 (1): 25-53.

Cinar, Didem and Gulgun Kayakutlu (2010): Scenario Analysis Using Bayesian Networks: A Case Study in Energy Sector, Knowledge-Based Systems, 23 (3): 267-276.

Cowell, Robert G., Richard J. Verrall, and Y. K. Yoon (2007): Modeling Operational Risk with Bayesian Networks, Journal of Risk and Insurance, 74 (4): 795-827.

Davies, Jonathan, Mike Finlay, Tara McLenaghen, and Duncan Wilson (2006): Key Risk Indicators: Their Role in Operational Risk Management and Measurement, in: Ellen Davis (ed.): The Advanced Measurement Approach to Operational Risk, Risk Books: London, UK, 215-246.
Day, George S. and Paul J. H. Schoemaker (2005): Scanning the Periphery, Harvard Business Review, 83 (11): 135-148.

DiCicco-Bloom, Barbara and Benjamin F. Crabtree (2006): The Qualitative Research Interview, Medical Education, 40 (4): 314321.

Diliello, Trudy C., Jeffery D. Houghton, and David Dawley (2011): Narrowing the Creativity Gap: The Moderating Effects of Perceived Support for Creativity, Journal of Psychology, 145 (3): 151172.

Dreyfus, Hubert L. and Stuart E. Dreyfus (2005): Peripheral Vision: Expertise in Real World Contexts, Organization Studies, 26 (5): 779-792.

Duncan, Robert B. (1972): Characteristics of Organizational Environments and Perceived Environmental Uncertainty, Administrative Science Quarterly, 17 (3): 313-327.

Eden, Colin, Sue Jones, David Sims, and Tim Smithin (1981): The Intersubjectivity of Issues and Issues of Intersubjectivity, Journal of Management Studies, 18 (1): 37-47.

Ediger, Volkan S. and Sertac Akar (2007): ARIMA Forecasting of Primary Energy Demand by Fuel in Turkey, Energy Policy, 35 (3): 1701-1708.

Ericsson, K. Anders, Michael J. Prietula, and Edward T. Cokely (2007): The Making of an Expert, Harvard Business Review, 85 (7/8): 114-121.

Fontela, Emilio (1976): Industrial Applications of Cross-Impact Analysis, Long Range Planning, 9 (4): 29-33.

Frolick, Mark N., Monica J. Parzinger, R. Kelly Rainer Jr., and Narender K. Ramarapu (1997): Using EISs for Environmental Scanning, Information Systems Management, 14 (1): 35-40.

Garg, Vinay K., Bruce A. Walters, and Richard L. Priem (2003): Chief Executive Scanning Emphases, Environmental Dynamism, and Manufacturing Firm Performance, Strategic Management Journal, 24 (8): 725-744.

Gregor, Shirley (2006): The Nature of Theory in Information Systems, MIS Quarterly, 30 (3): 611-642.

Gutzwiller, Thomas (1994): Das CC RIM-Referenzmodell für den Entwurf von betrieblichen, transaktionsorientierten Informationssystemen, Physica: Heidelberg.

Hevner, Alan R., Salvatore T. March, Jinsoo Park, and Sudha Ram (2004): Design Science in Information Systems Research, MIS Quarterly, 28 (1): 75-105.

Jensen, Finn V. and Thomas D. Nielsen (2007): Bayesian Networks and Decision Graphs, Springer: Berlin et al.

Kajüter, Peter (2004): Die Regulierung des Risikomanagements im Internationalen Vergleich, Controlling und Management, 48 (3 Supplement): 12-25.

Kaplan, Robert S. and David P. Norton (1992): The Balanced Scorecard: Measures That Drive Performance, Harvard Business Review, 70 (1): 71-79.

Kornmeier, Martin (2007): Wissenschaftstheorie und Wissenschaftliches Arbeiten: Eine Einführung für Wirtschaftswissenschaftler, Physica: Heidelberg.

Kreilkamp, Edgar (1987): Strategisches Management und Marketing: Markt- und Wettbewerbsanalyse, Strategische Frühaufklärung, Portfolio-Management, De Gruyter: Berlin.

Krishnan, Jagan, Dasaratha V. Rama, and Yinghong Zhang (2008): Costs to Comply with SOX Section 404, Auditing: $A$ Journal of Practice \& Theory, 27 (1): 169-186.

Kuo, Ren J. and K. C. Xue (1998): A Decision Support System for Sales Forecasting Through Fuzzy Neural Networks with Asymmetric Fuzzy Weights, Decision Support Systems, 24 (2): 105-126. 
Lam, Monica (2004): Neural Network Techniques for Financial Performance Prediction: Integrating Fundamental and Technical Analysis, Decision Support Systems, 37 (4): 567-581.

Lane, David C. (2000): Should System Dynamics Be Described as a 'Hard' or 'Deterministic' Systems Approach?, Systems Research and Behavioral Science, 17 (1): 3-22.

Lauria, Eitel J. M. and Peter J. Duchessi (2006): A Bayesian Belief Network for IT Implementation Decision Support, Decision Support Systems, 42 (3): 1573-1588.

Leigh, William, Russell Purvis, and James M. Ragusa (2002): Forecasting the NYSE Composite Index with Technical Analysis, Pattern Recognizer, Neural Network, and Genetic Algorithm: A Case Study in Romantic Decision Support, Decision Support Systems, 32 (4): 361-377.

Lenz, R. T. and Jack L. Engledow (1986): The Applicaibility of Current Theory, Strategic Management Journal, 7 (4): 329-346.

Lesca, Nicolas and Marie-Laurence Caron-Fasan (2008): Strategic Scanning Project Failure and Abandonment Factors: Lessons Learned, European Journal of Information Systems, 17 (4): $371-386$.

Levanon, Gad (2010): Evaluating and Comparing Leading and Coincident Economic Indicators, Business Economics, 45 (1): 1627.

Li, Lianfa, Jinfeng Wang, Hareton Leung, and Chengsheng Jiang (2010): Assessment of Catastrophic Risk Using Bayesian Network Constructed from Domain Knowledge and Spatial Data, Risk Analysis, 30 (7): 1157-1175.

Liu, Shuhua (2000): Agent Based Environmental Scanning System: Impacts on Managers and Their Strategic Scanning Activities, AMCIS 2000 Proceedings, Paper 173, http:// aisel.aisnet.org/amcis2000/173 (Access date: 2013-06-27).

Lyneis, James M. (2000): System Dynamics for Market Forecasting and Structural Analysis, System Dynamics Review, 16 (1): 3-25.

Makridakis, Spyros, Robin M. Hogarth, and Anil Gaba (2010): Why Forecasts Fail: What to Do Instead?, MIT Sloan Management Review, 51 (2): 83-90.

March, Salvatore T. and Gerald F. Smith (1995): Design and Natural Science Research on Information Technology, Decision Support Systems, 15 (4): 251-266.

Mayer, Jörg H. (2012): Powering Up Companies' Crystal Balls: Analysis Of A Multicase Study Towards More Applicable Environmental Scanning Systems, ECIS 2012 Proceedings, Paper 97, http://aisel.aisnet.org/ecis2012/97 (Access date: 2013-06-26).

Mayer, Jörg H., Neon Steinecke, and Reiner Quick (2011): Improving the Applicability of Environmental Scanning Systems: State of the Art and Future Research, in: Markus Nuettgens, Andreas Gadatsch, Karlheinz Kautz, Ingrid Schirmer, and Nadine Blinn (eds): Governance and Sustainability in Information Systems: Managing the Transfer and Diffusion of IT, Springer: Heidelberg et al., 207-223.

Mayer, Jörg H., Neon Steinecke, Reiner Quick, and Timm Weitzel (2012): More Applicable Environmental Scanning Systems Leveraging „Modern” Information Systems, http://link.springer. com/article/10.1007/s10257-012-0207-7 (Access date: 2013-0702).

McDoniel, Phillip B. and Patrick J. Monteleone (2001): Simulation and Optimisation in Direct Marketing. Part 1: Using Simulation Models to Develop Forecasts, Journal of Database Marketing, 9 (1): 35-44.

Merritt, Thomas P. (1974): Forecasting the Future Business Environment: The State of the Art, Long Range Planning, 7 (3): 54-62.
Myers, Michael D. and Michael Newman (2007): The Qualitative Interview in IS Research: Examining the Craft, Information and Organization, 17 (1): 2-26.

Nadkarni, Sucheta and Fiona Fui-Hoon Nah (2003): Aggregated Causal Maps: An Approach to Elicit and Aggregate the Knowledge of Multiple Experts, Communications of the Association for Information Systems, 12: 406-436.

Nadkarni, Sucheta and Prakash P. Shenoy (2001): A Bayesian Network Approach to Making Inferences in Causal Maps, European Journal of Operational Research, 128 (3): 479-498.

Nadkarni, Sucheta and Prakash P. Shenoy (2004): A Causal Mapping Approach to Constructing Bayesian Networks, Decision Support Systems, 38 (2): 259-281.

Narchal, R. M., K. Kittappa, and P. Bhattacharya (1987): An Environmental Scanning System for Business Planning, Long Range Planning, 20 (6): 96-105.

Olson, David L., Dursun Delen, and Yanyan Meng (2012): Comparative Analysis of Data Mining Methods for Bankruptcy Prediction, Decision Support Systems, 52 (2): 464-473.

Österle, Hubert, Jörg Becker, Ulrich Frank, Thomas Hess, Dimitris Karagiannis, Helmut Krcmar, Peter Loos, Peter Mertens, Andreas Oberweis, and Elmar J. Sinz (2010): Memorandum zur gestaltungsorientierten Wirtschaftsinformatik, Schmalenbachs Zeitschrift für betriebswirtschaftliche Forschung, 62 (6): 664672.

Peffers, Ken, Tuure Tuunanen, Charles E. Gengler, Matti Rossi, Wendy Hui, Ville Virtanen, and Johanna Bragge (2006): The Design Science Research Process: A Model for Producing and Presenting Information Systems Research, http://6a.1b.7aae. static.theplanet.com/sites/default/files/documents/ooodesignscr esearchproc_desrist_2006.pdf (Access date: 2013-06-26).

Porter, Michael E. and Victor E. Millar (1985): How Information Gives You Competitive Advantage, Harvard Business Review, 63 (4): 149-160.

Pourret, Olivier, Patrick Naim, and Bruce Marcot (2008): Bayesian Networks: A Practical Guide to Applications, Wiley: Chichester, UK.

Rohrbeck, Rene (2012): Exploring Value Creation from Corporate-Foresight Activities, Futures, 44 (5): 440-452.

Sanford, Andrew D. and Imad A. Moosa (2012): A Bayesian Network Structure for Operational Risk Modelling in Structured Finance Operations, Journal of the Operational Research Society, 63 (4): 431-444.

Sarkar, Sumit and Ram S. Sriram (2001): Bayesian Models for Early Warning of Bank Failures, Management Science, 47 (11) 1457-1475.

Scavarda, Annibal J., Tatiana Bouzdine-Chameeva, Susan M. Goldstein, Julie M. Hays, and Arthur V. Hill (2006): A Methodology for Constructing Collective Causal Maps, Decision Sciences, 37 (2): $263-283$.

Schadt, Eric E., Michael D. Linderman, Jon Sorenson, Lawrence Lee, and Garry P. Nolan (2010): Computational Solutions to Large-Scale Data Management and Analysis, Nature Reviews Genetics, 11 (9): 647-657.

Sherman, W. Scott and Valrie Chambers (2009): SOX as Safeguard and Signal: The Impact of the Sarbanes-Oxley Act of 2002 on US Corporations' Choice to List Abroad, Multinational Business Review, 17 (3): 163-180.

Shirazi, Mohsen A. and Javad Soroor (2007): An Intelligent Agent-Based Architecture for Strategic Information System Applications, Knowledge-Based Systems, 20 (8): 726-735.

Simon, Herbert A. (1996): The Sciences of the Artificial, $3^{\text {rd }}$ ed., MIT Press: Cambridge et al., MA. 
Sommerville, Ian (2007): Software Engineering, Addison-Wesley: Harlow et al., UK.

Spender, J.-C. and Bernard Marr (2005): A Knowledge-Based Perspective on Intellectual Capital, in: Bernard Marr (ed.): Perspectives on Intellectual Capital, Elsevier: Amsterdam, 183-195.

Stratford, Jean S. (1988): United States Economic Indicators: Definitions, Sources and Resources, Government Publications Review, 15 (3): 231-236.

Sun, Lili and Prakash P. Shenoy (2007): Using Bayesian Networks for Bankruptcy Prediction: Some Methodological Issues, European Journal of Operational Research, 180 (2): 738-753.

Sundstrom, Eric, Paul L. Busby, and Warren S. Bobrow (1997): Group Process and Performance: Interpersonal Behaviors and Decision Quality in Group Problem Solving by Consensus, Group Dynamics: Theory, Research, and Practice, 1 (3): 241-253.

Vom Brocke, Jan (2003): Referenzmodellierung, Gestaltung und Verteilung von Konstruktionsprozessen, Logos: Berlin.

Vom Brocke, Jan, Alexander Simons, Björn Niehaves, Kai Riemer, Ralf Plattfaut, and Anne Cleven (2009): Reconstructing the Giant: On the Importance of Rigour in Documenting the Literature Search Process, ECIS 2009 Proceedings, Paper 372, http:// aisel.aisnet.org/ecis2009/372 (Access date: 2013-06-27).

Webster, Jane and Richard T. Watson (2002): Analyzing the Past to Prepare for the Future: Writing a Literature Review, MIS Quarterly, 26 (2): xiii-xxiii.

Wong, Man L. and Yuan Y. Guo (2008): Learning Bayesian Networks from Incomplete Databases Using a Novel Evolutionary Algorithm, Decision Support Systems, 45 (2): 368-383.

Yasai-Ardekani, Masoud and Paul C. Nystrom (1996): Designs for Environmental Scanning Systems: Tests of a Contingency Theory, Management Science, 42 (2): 187-204.
Yin, Robert K. (2009): Case Study Research: Design and Methods, $4^{\text {th }}$ ed., Sage: Los Angeles et al., CA.

\section{Biographies}

Simon Welter was a research student at Darmstadt University of Technology and is now a management consultant at A.T. Kearney GmbH, Frankfurt/Main, Germany. He holds a bachelor's degree in Business Administration and Mechanical Engineering from Darmstadt University of Technology, Germany. His research interests are environmental scanning systems, decision making and decision support systems.

Jörg H. Mayer is the project manager of the "Corporate Management Systems" Competence Center at the Institute of Information Management, University of St. Gallen, Switzerland (http://uss.iwi.unisg.ch). In parallel, he is a Global Expert within the Business Technology Office of McKinsey \& Company Inc., Frankfurt/Main, Germany. He received his Doctoral Degree in 1999 at Darmstadt University of Technology. His main research interests are executives and their information systems support, especially mobile corporate business intelligence and environmental scanning systems.

Reiner Quick has been Professor and the Chair of Accounting and Auditing at Darmstadt University of Technology since 2004 as well as a part-time Professor of Auditing at the University of Southern Denmark since 2009. He received his Doctoral Degree in 1990 and his Habilitation in 1995 at the University of Mannheim, and held full professorships at the University of Essen and the Westfälische Wilhelms-Universität Münster. His main areas of research are auditing, in particular audit methodology, auditor independence and audit markets, and management accounting. 